\title{
Effect of fat tail docking on meat quality of Awassi sheep in comparison with Lacaune sheep
}

\author{
Lina FARAH ${ }^{1,2,3, *}$, Rabih El RAMMOUZ ${ }^{2}$, Edouard TABET ${ }^{1,2}$, Claudine LAHOUD ${ }^{2}$, Saab \\ ABI SAAB ${ }^{3}$ \\ ${ }^{1}$ CRAF: Center of Research and Agriculture Formation/Lebanese University, Ghazir- Lebanon; \\ 2 Faculty of Agriculture and Veterinary Medicine/ Lebanese University, Beirut-Lebanon; \\ ${ }^{3}$ Université Saint Esprit Kaslike, Kaslik- Lebanon; \\ * Corresponding author: Lina FARAH; lina.f.azar@gmail.com.
}

Key words: Awassi sheep, fat tail docking, Lacaune sheep, meat quality.

Publication date 31/07/2019, http://www.m.elewa.org/JAPS

\section{ABSTRACT}

This experiment was conducted to study the effect of fat tail docking on Awassi lamb sheep's meat in comparison with thin-tail Lacaune sheep's meat (imported breed in Lebanon). Twenty seven ram lambs were divided into three groups, intact fat-tail Awassi (IA), docked fat-tail Awassi (DA), and imported thin-tail Lacaune (IL). Docking was performed at one week of age, by applying tight rubber rings on the tail. Animals having the same body weight were slaughtered at one year of age. Three samples of muscles were excised from each carcass; Biceps Femoris (Bf), Longissimus Dorsii $(L d)$ and Gluteus Medius $(G m)$. Samples were wrapped in an oxygen permeable film and stored at $4^{\circ} \mathrm{C}$ and $30^{\circ} \mathrm{C}$ for the assessment of $\mathrm{pH}$, and meat quality traits. The ultimate $\mathrm{pH}$ was significantly higher $(P<0.01)$ in Lacaune breed as compared to both docked and intact Awassi breed. DA animals had significantly higher $(P<0.01)$ fat content in $L d$ muscle than IA and IL lambs. Both Awassi groups presented higher $L^{*}$ values than Lacaune animals $(P<0.05)$. In addition for Awassi breed, $L^{*}$ values of $B f$ and $G m$ muscles were significantly greater $(P<$ $0.05)$ than that of $L d$ muscle. $b^{*}$ values were significantly greater $(P<0.05)$ in $G m$ of all animals under study. Lacaune group had lower drip loss values than Awassi groups $(P<0.05$ in $B f$ and $G m$ muscles and $P<0.01$ in $L d$ muscle). However for Awassi breed, the drip loss in $L d$ muscle of DA animals was significantly lower $(P<0.01)$ than IA ones. Furthermore, thawing and cooking losses were neither affected by breed nor by docking. Regarding the PND values, the $L d$ muscle of DA group presented higher values $(P<0.05)$ than $B f$ and $G m$ muscles of both intact groups. In addition, cooked meat PND values were significantly higher $(P<0.05)$ in $L d$ muscle of DA when compared to intact groups. Due to the scarcity of information in this area of research, further investigations are needed.

\section{INTRODUCTION}

Awassi is the most widespread sheep breed of non- European origin (Galal et al., 2008). They are large framed, fat tailed sheep mostly grown and consumed in the Middle East countries (Abdelqader et al., 2017). The fat tail plays an important role in adaptation of sheep raised under the harsh feeding conditions of arid and semi- arid regions, where the availability of food- stuff is seasonal (Vatankah and Talebi, 2008). Awassi sheep are known to deposit $20 \%$ of their carcass weight as fat in the tail which has traditionally been used as source of cooking fat (Yousefi et al., 2012). Awassi sheep have desirable carcass traits and meat quality (Holloway et al., 1994), especially because the presence of the fat tail which allows for leaner 
carcasses and makes it easier to trim any undesirable fat. The fat stored in the tail may contribute to the lower level of fat found elsewhere in various cuts compared to more traditional sheep breeds (Safdarian et al., 2008). Fat tailed lambs store fat in their tail and they tend to have lower amount of carcass and muscular fat (Webb and O'Neill, 2008). Awassi lamb's meat had lower dry matter and crude fat percentages than other genotypes (Abdullah et al., 2011). Despite their high demand in the Mediterranean and Arabian Gulf region yet they produce a very small proportion of lamb and mutton. The self- sufficiency of highly preferred locally produced lambs in the area of fat-tailed sheep ranges from 10 to $12 \%$ (NikKhah, 1984). This deficit obliges the market to import thin- tail lamb from Europe and Australia. Moreover, the market price of fat-

\section{MATERIALS AND METHODS}

3.1 Animals: A total of $27 \mathrm{ram}$ lambs were raised at the Center of Research and Agriculture Formation (CRAF) in Ghazir, till one year of age (2018-2019) under conventional breeding conditions and nutrition. Males were divided into 3 equal groups; 2 groups of fat tail Awassi sheep (intact "IA" and docked "DA") and a group of imported thin- tail Lacaune sheep (IL). Docking was performed at one week of age, by applying tight tailed sheep meat is two to three times higher than that of thin- tailed sheep (FAO, 2015). Many researchers e.g. Abi Saab et al. (2010) have studied the effect of fat tail on the reproductive characteristics of Awassi breed. The objectives of docking fat tail in lambs are to improve reproductive skills, feed efficiency, live body weight gain and to facilitate natural mating with non- fat- tailed breeds (Farah et al., 2019). To the best of our knowledge, experimental data on the effect of fat tail docking on meat quality in ovine and especially in Awassi sheep are scarce. Furthermore, fat tail docking is thought to be desirable for increasing the organoleptic properties of lamb's meat (Moharrery, 2007). Therefore, the present experiment was carried out on Awassi and Lacaune sheep to study the effect of fat tail docking on meat quality and compare it with thin- tail sheep.

rubber ring on the tail at the distal end of the caudal fold (between the first and the second vertebrae down the tail). Animals were withdrawn for 24 hours, transported for $1.5 \mathrm{~h}$ and allowed to rest for $1 \mathrm{~h}$ before being slaughtered according to standard commercial procedure (captive bolt stunning, no electrical stimulation). Table 1 summarizes some characteristics of the animals within groups at slaughter.

Table. 1: Summary of animals ${ }^{1}$ at slaughter.

\begin{tabular}{|c|c|c|c|c|c|}
\hline Breeds & Number of lambs & $\begin{array}{l}\text { Fasting } \\
\text { (h) }\end{array}$ & $\begin{array}{l}\text { Transportation } \\
\text { (h) }\end{array}$ & $\begin{array}{l}\text { Live body } \\
\text { weight (Kg) }\end{array}$ & $\begin{array}{l}\text { Carcass weight } \\
\text { (kg) }\end{array}$ \\
\hline $\begin{array}{l}\text { Awassi } \\
\text { IA } \\
\text { DA } \\
\text { Lacaune } \\
\text { IL }\end{array}$ & $\begin{array}{l}9 \\
9\end{array}$ & $\begin{array}{l}24 \\
24\end{array}$ & $\begin{array}{l}1.5 \\
1.5\end{array}$ & $\begin{array}{l}51.54 \pm 3.74 \\
52.32 \pm 4.01 \\
53.71 \pm 3.99\end{array}$ & $\begin{array}{l}22.76 \pm 2.17 \\
23.0 \pm 2.54 \\
23.15 \pm 2.33\end{array}$ \\
\hline
\end{tabular}

1, IA, intact Awassi lambs; DA, docked Awassi lambs; IL, intact Lacaune lambs.

3.2 Muscle sampling: After 30 minutes of dressing, the right femoral muscle (Biceps femoris " $B f$ '), the loin muscle (Longissimus dorsii ' $L d$ ') and the sirloin muscle (Gluteus medius "Gm") were excised from the carcass of each animal. Two similar size cuts of $L d$ and $G m$ muscles were packed and stored at $4^{\circ} \mathrm{C}$ and $-30^{\circ} \mathrm{C}$, respectively. Whereas, 2 slices of approximately $300 \mathrm{~g}$ each with similar size and shape were cut from the right femoral muscle; one slice was stored at $4^{\circ} \mathrm{C}$, while the other one was vacuum-packed, frozen and conserved at $30^{\circ} \mathrm{C}$ to determine the meat quality after freezing/ defrosting.

3.3 Ultimate $\mathrm{pH}$ measurements: At 2 different post mortem times (24 and 48 hours) and after cooking, the ultimate $\mathrm{pH}$ of each muscle was determined as described by Jeacocke (1977). Approximately, $2 \mathrm{~g}$ of muscle were homogenized in 
$18 \mathrm{ml}$ of $5 \mathrm{mM}$ iodoacetate buffer. The $\mathrm{pH}$ of the homogenate was measured using a $\mathrm{pH}$ meter (WTW $720 \mathrm{pH}$ meter) equipped with a combined electrode (Sen Tix 21) and an average of 2 replications by sample was calculated.

\subsection{Meat quality}

3.4.1 Fat: Petroleum ether extraction method was performed to determine the meat fat content as described by the Association for Official and Analytical Chemists (AOAC, 1995). Approximately, 5 grams of muscle were grinded until obtaining a homogeneous mass, and put in a filter paper then in a drying oven (SELECTA 295057; from 0 to $250^{\circ} \mathrm{C}$ ) at $105^{\circ} \mathrm{C}$ for 60 minutes. Dried samples were then cooled for 15 minutes in a desiccator (KARTTEL) and weighed. Later on, filter papers were transferred into a Soxhlet equipment and placed in the extractor flask containing the petroleum ether solvent. After heating and cooling, the solvent trickles dissolve the fats and within 10 to 12 hours the fat extraction finishes. Total fat were expressed in gram/ per $100 \mathrm{~g}$ of fresh tissue.

3.4.2 Colour: Meat color was determined using a chromameter (ADCI-60-C; Beijing, China). The instrument was set to measure using the CIE system values of luminance $\left(\mathrm{L}^{*}\right)$, redness $\left(\mathrm{a}^{*}\right)$, and yellowness $\left(\mathrm{b}^{*}\right)$ using illuminate $\mathrm{D}$ and $65^{\circ}$ standard observer (CIE, 1986). All measurements (3 replicates on each sample) were carried out at 2 different post mortem times (24 and 48 hours) and after cooking on the surface of each sample, in an area free of obvious color defects (over scalding, blood spots, and haemorrhages).

3.4.3 Water holding capacity (WHC): Drip, thawing and cooking losses were determined as described by Honikel (1998). Cuts of Bf, $L d$ and $G m$ were weighed at the time of collection (approximately 30 minutes post mortem) placed in a polystyrene tray, wrapped in an oxygen permeable film and kept at $4^{\circ} \mathrm{C}$. Meat cuts were reweighed at 48 hours post mortem and the drip loss was expressed

\section{RESULTS AND DISCUSSION}

4.1 Muscle ultimate $\mathrm{pH}$ : As shown in figure 1 , the ultimate $\mathrm{pH}$ of all muscles in IL animals, was significantly higher than in IA and DA sheep $(P<$ 0.01). In fact, at $48 \mathrm{~h}$ post mortem the $B f$ muscle of DA was significantly the lowest (DA: $5.56 \pm 0.04$ vs. IA: $5.61 \pm 0.04$ and IL: 6.03 \pm 0.06. $P<0.01$ ), in addition and after cooking, both Awassi groups (Intact and docked) had lower $B f$ muscle's $\mathrm{pH}$ then

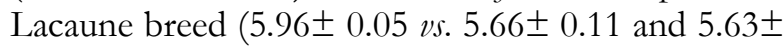

as percentage of initial weight. After $12 \mathrm{~h}$ thawing at $4^{\circ} \mathrm{C}$, cuts from $B f, L d$ and $G m$ muscles were taken from bags, dried with filter paper, and reweighed before cooking. Thawing loss was expressed as a percentage of the frozen weight. Cooking loss was determined immediately after thawing; cuts (from $L d$ and $G m$ muscles) were vacuum- packed in polyethylene bags and cooked in a water bath at $80^{\circ} \mathrm{C}$ for 15 minutes corresponding to an internal temperature of $70^{\circ} \mathrm{C}$. Samples were cooled for 45 minutes under running tap water at room temperature. After that, they were taken from the bags, dried with filter paper and weighed. Cooking loss was expressed as the percentage loss relative to the weight immediately before cooking.

3.4.4 Texture: Texture was measured using a penetrometer (interface RS232C) with a needle of $2.5 \mathrm{~g}$ based on a weight of $97.5 \mathrm{~g}$, thus attaining a total weight of $100 \mathrm{~g}$. The measurements were performed at different post mortem times (3, 12, 24, 48, 72, 144 hours and after cooking). The penetration was carried out on meat slices $(3 \mathrm{~cm} \times$ $2 \mathrm{~cm} \times 1 \mathrm{~cm})$ prepared such that the longest dimension was parallel to the fiber axis. Slices were placed on a horizontal support and the force of the needle was applied perpendicularly to the muscle fibers for 5 seconds (Becila, 2002). The penetrometer needle depth (PND; in $\mathrm{mm}$ ) was recorded and an average of 3 replications by sample was calculated.

3.5 Statistical analysis: ANOVA was carried out using the GLM procedure of SPSS 16.0. The model included the effects of breed, docking and muscle type. When significant effects were recorded, mean values were compared using Duncan's multiple range tests. All results were reported as mean \pm standard deviation $(\mu \pm \mathrm{Sd})$. In graphs, vertical bars indicate standard deviation (Sd).

0.06; $P<0.01$ ). Moreover, at $48 \mathrm{~h}$ post mortem $\mathrm{Ld}$ muscle's $\mathrm{pH}$ of docked lambs was significantly lower than Lacaune, and slightly lower than IA (5.66 0.03 vs. $5.95 \pm 0.08$ and $5.68 \pm 0.07 ; P=0.07$ ). Finally at $48 \mathrm{~h}$ post mortem for the $\mathrm{Gm}$ muscle's $\mathrm{pH}$, the values of IL breed were significantly higher than Awassi both docked and intact groups (5.93 \pm 0.04 vs. $5.58 \pm 0.07$ and $5.54 \pm 0.03 ; \quad \mathrm{P}<0.05)$. In conclusion, for the present study the mean ultimate 
$\mathrm{pH}$ in all muscles of Lacaune Breed was above 5.8 and values ranged between 5.60 and 6.79 , whereas, Awassi groups (IA and DA) presented lower ultimate $\mathrm{pH}$ values varying between 5.51 and 5.77 . Results of the present research suggested that ultimate $\mathrm{pH}$ of meat in Awassi sheep is not affected by fat tail docking. Those results are in agreement with Wang et al. (2018) who stated that tail docking does not affect the ultimate $\mathrm{pH}$ (measured at $24 \mathrm{~h}$ post mortem) of $L d$ and $G m$ muscles in sheep. However Awassi lambs (IA or DA) have a significant lower ultimate $\mathrm{pH}$ (at 24 and $48 \mathrm{~h}$ post mortem) in Bf, $L d$ and $G m$ muscles than Lacaune breed, thus affected by breed. These variations in the ultimate $\mathrm{pH}$ of different breeds could be explained by the fact that sheep of various genetic types had different peri mortem glycogen content. Indeed, as muscle is converted into meat, the stored glycogen is anaerobically degraded to lactic acid and the extent of post mortem $\mathrm{pH}$ decline is determined by the accumulation of lactate and consequently the content of muscle glycogen at slaughter. In agreement with this assertion, the high mean ultimate $\mathrm{pH}$ value detected in the present study in Lacaune breed meat could be attributed to the low glycogen muscle concentration in IL animals as compared to Awassi breed. Those results agreed with Hoffman et al. (2003) and Jandasek et al. (2014) who confirmed the effect of breed on the ultimate $\mathrm{pH}$ of meat; they reclaim that some sheep breeds are less resistant to pre-slaughter stresses than others leading to different rates and extents of post mortem $\mathrm{pH}$ fall. Similarly, while studying meat quality in different lamb breeds, Martinez- Cerezo et al. (2005) found $\mathrm{pH}$ differences. In contrast those results don't agree with, Hernandez- Cruz et al.
(2009) who reported that the ultimate $\mathrm{pH}$ measured at $24 \mathrm{~h}$ post mortem is not affected by ovine breeds. Furthermore Hopkins et al. (2011) assumed that values of red meat ultimate $\mathrm{pH}$ greater than 5.8 affect negatively the bacteriological stability, the shelf life, the flavor and the aroma of meat. Since the ultimate $\mathrm{pH}$ of Awassi and Lacaune sheep meat were, respectively, lower and higher than 5.8 (ranging between 5.51 and 5.77 for Awassi breed and 5.60 and 6.79 for Lacaune sheep), it could be suggested that Awassi sheep meat has a longer shelf life and a better flavor and aroma than Lacaune sheep. Finally this experiment result's agree with Esenbuga et al. (2009) and Abdullah et al. (2011), who reported that after the cessation of blood circulation and oxygen supply, lactic acid accumulates in $L d$ muscle of fat tailed sheep resulting in a $\mathrm{pH}$ drop from 6.33 to 5.64 at 24 hours post mortem. Concerning the effect of muscle type on ultimate $\mathrm{pH}$ in lamb's meat (Tab.2.), the values differed significantly among the 3 muscle types $(P<$ $0.05)$. In Awassi lambs (IA and DA), the $L d$ muscle showed the highest ultimate $\mathrm{pH}$ while, in Lacaune animals, the ultimate $\mathrm{pH}$ was the lowest in the $G m$ muscle. These findings are consistent with the work of Ablikim et al. (2016) who noticed significant differences in the ultimate $\mathrm{pH}$ of $B f, L d$ and $G m$ muscles in different sheep breeds. These variations in muscle $\mathrm{pH}$ may result from differences in the proportion of red (STO: Slow Twitch Oxidative) and white (FTOG: Fast Twitch Oxidative Glycolytic; FTG: Fast Twitch Glycolytic) muscle fibers which had different contractile and metabolic properties and different glycogen content and ATP stores.

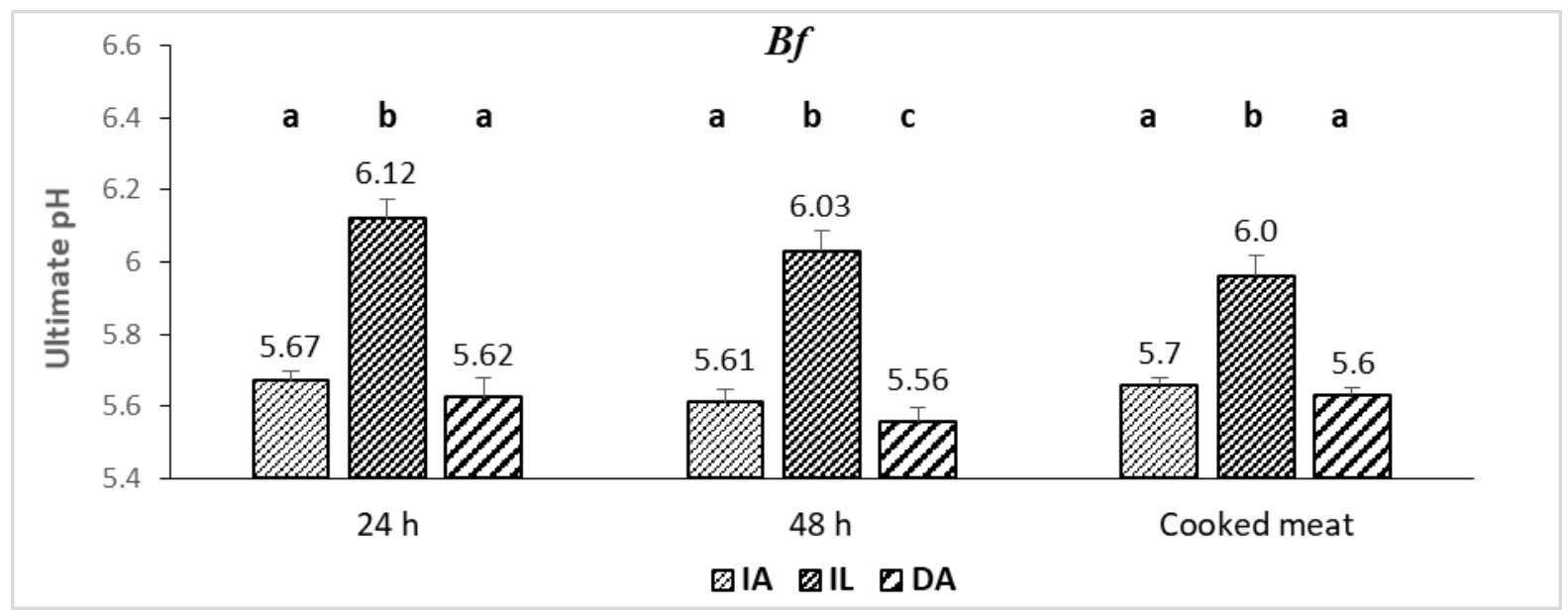




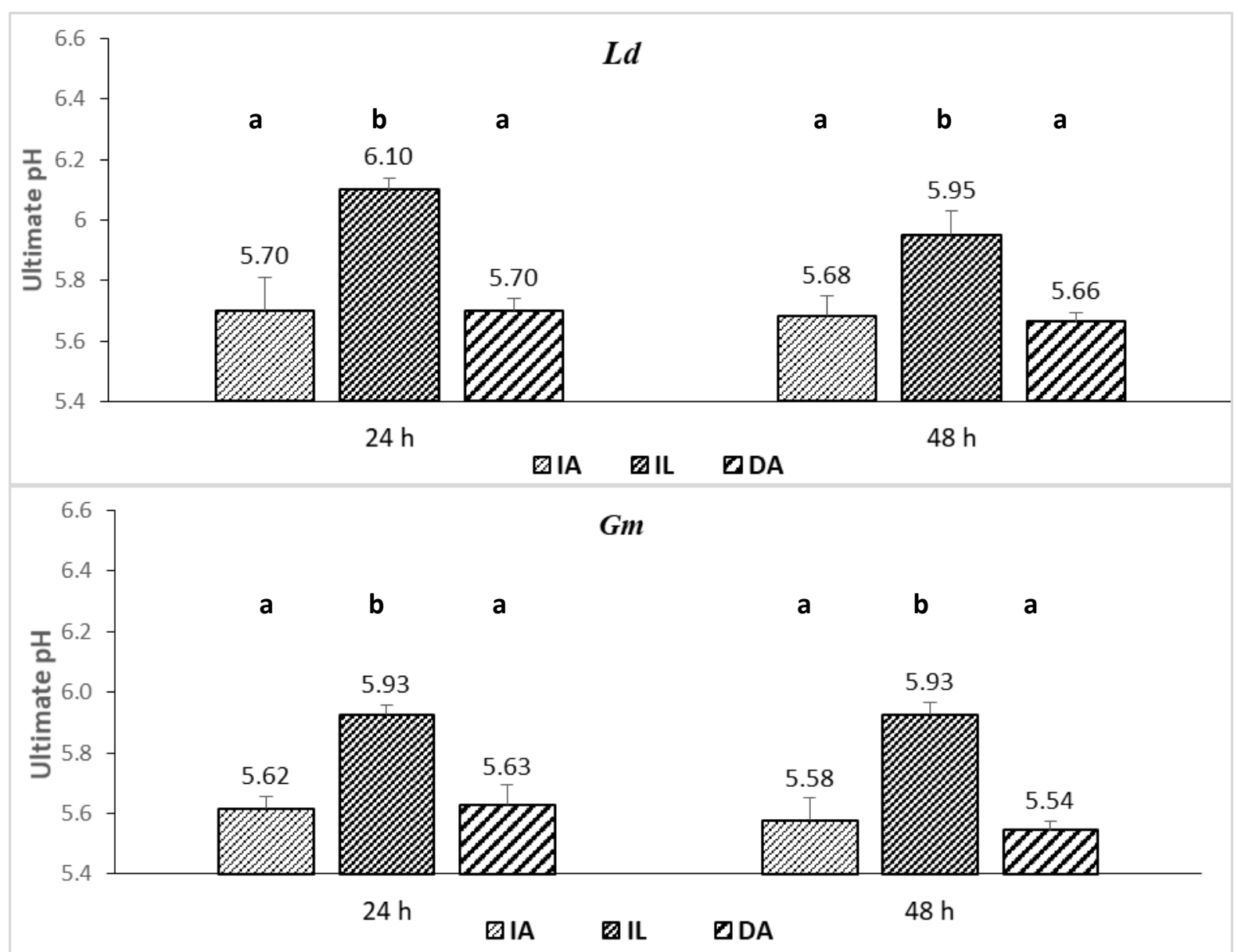

Figure. 1: Effect of breed and fat tail docking on ultimate $\mathrm{pH}$ (measured at 24 and 48 hours post mortem and after cooking) in $B f, L d$, and $G m$ muscles of sheep lambs. a, b, c, different letters indicate significant difference at $P<0.01$.

Table. 2: Effect of muscle type ${ }^{1}$ on ultimate $\mathrm{pH}$ (measured at 24 and $48 \mathrm{~h}$ post mortem) in Awassi (IA), tail docked Awassi (DA) and Lacaune (IL) sheep.

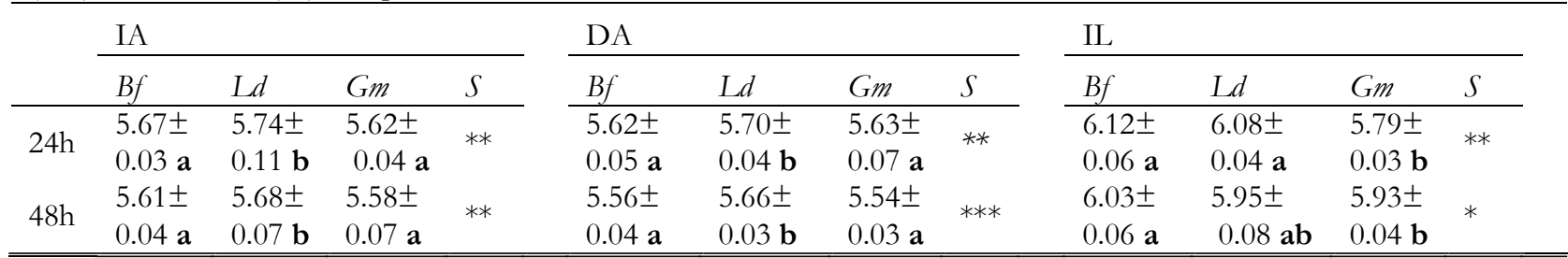

1, Bf, Ld, Gm, Biceps femoris, Longissimus dorsii, Gluteus medius;

a, b, within the same row, indicate significant differences at $P<0.05^{*}, P<0.01 * *$, and $P<0.001 * * * ; N S, P>0.05$.

\subsection{Meat quality attributes}

4.2.1 Fat: The present work (Tab. 3.) showed that the breed did not affect the meat fat concentration in sheep. Whereas, tail docking influenced the deposition of fat in Awassi sheep muscles. Moreover, in $L d$ muscle, DA animals had a significant higher fat content $(P<0.01)$ than IA and IL groups $(5.18 \pm 0.15 \mathrm{Vs} .3 .76 \pm 0.16$ and $4.08 \pm 0.5$ $\mathrm{g} / 100 \mathrm{~g}$, respectively; $P<0.01$ ). However, no significant effect of docking on muscle fat deposition was detected in $B f$ and $G m$ muscle. That is to say, docking affected significantly fat content in the $L d$ muscles mainly. Findings of the current work coincided with the observations of Kyanzad (2001) who published that the loss of fat tail in sheep is compensated by an increase in sub-cutaneous muscle and internal fat percentages. Moreover, Safdarian et al. (2008) reported that fat-tailed sheep generally had lower proportions of carcass and muscle fat depots than docked lambs. Indeed Webb 
and O’Neill (2008), confirmed that tail docking increases the carcass fat accumulation including skeletal muscle. Likewise, Wang et al. (2018) observed that rump and epiploic fat weights were increased in docked lambs as were $L d$ and $G m$ muscles fat comparing to undocked sheep. Besides, when evaluating the effect of muscle type on fat content, this trial detected that, in IA and IL groups, $G m$ muscle showed the highest fat concentration, whereas $\mathrm{Ld}$ the lowest and $\mathrm{Bf}$ muscle an intermediate value, $(P<0.001)$. Whereas, in $\mathrm{DA}$ lambs, the $G m$ muscle exhibited the highest fat content $(8.06 \pm 0.73 \mathrm{~g} / 100 \mathrm{~g})$ followed by $B f$ muscle (5.82 \pm 0.08$)$ and after the $L d(5.18 \pm 0.15)$ with no significant difference between $B f$ and $L d$ muscles. These results were consistent with the findings of Abdullah et al. (2011) who noticed that meat fat content was affected by muscle types and that Awassi sheep were considered to have the lowest $L d$ muscle fat $\%$ in comparison with other breeds.

Table. 3: Fat content in $B f, L d$ and $G m$ muscles $^{1}$ of intact and tail docked Awassi (IA and DA, respectively) and Lacaune (IL) lambs sheep.

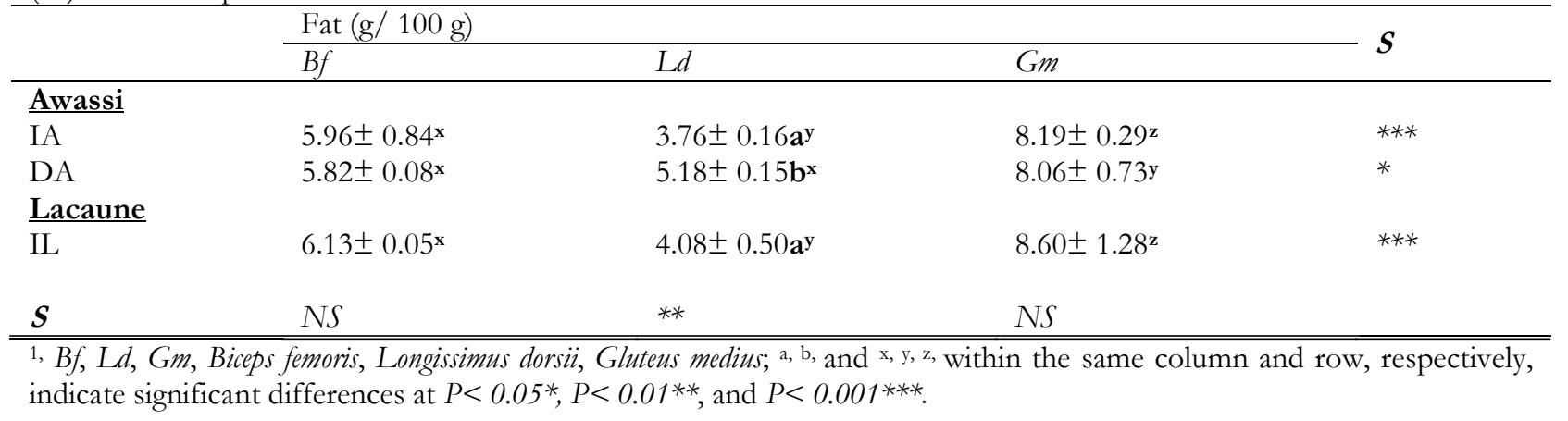

4.2.2 Colour: The present experiment showed that the breed affected significantly the color measurements (CIE: L*, $a^{*}, b^{*}$ ) of raw meat in sheep $(P<0.05)$. However, no significant influence of docking was detected on $\mathrm{L}^{*}, \mathrm{a}^{*}$ and $\mathrm{b}^{*}$ values (Tab. 4.). For a clearer presentation, the trichromatic coordinates (CIE values) measured on cooked meat are not shown in the table, since these parameters were not affected by treatments under study. Concerning L* values at all post mortem time, only breed (not docking) affected luminosity. Indeed Awassi lambs (docked and intact) presented higher values in all studied muscles than IL animals $(P<0.05)$. Muscle effect on luminosity showed that in Awassi sheep (IA and DA), luminosities of $B f$ and $G m$ muscles measured at all post mortem time were significantly greater $(P<0.05)$ than that of $L d$ muscle, with no significant difference recorded in Lacaune breed. Concerning the redness of meat, neither breed nor docking or type of muscle influenced $a^{*}$ values. Only a trend toward muscle effect was recorded in Lacaune breed, where $L d$ muscle tended to have higher $\mathrm{a}^{*}$ values than $B f$ and $G m$ muscles $(P=0.08)$. Regarding yellowness, b* values were significantly greater $(P<0.05)$ in $G m$ of all animals under study, as a result of muscle effect. In conclusion, this study confirmed that $\mathrm{L}^{*}$ is affected by both breed and muscle type, but not by docking; whereas, a* is neither affected by breed nor by docking, only muscle type had an effect on redness of Lacaune's meat; finally, yellowness is only affected by muscle type. Those findings don't agree with Esenbuga et al. (2009) who reported that lamb sheep genotypes did not affect the $\mathrm{L}^{*}$ and $\mathrm{a}^{*}$ values of meat. In contrast, our results agreed with Abdullah et al. (2011) who noted a significant difference among lamb breeds in lightness and redness of meat ( $\mathrm{L}^{*}$ and $\mathrm{a}^{*}$ values). Some authors admitted that the luminance of meat $\left(L^{*}\right)$ indicates the superficial light scattering and depends not only on post mortem $\mathrm{pH}$ fall but on redness and yellowness of meat as well, which are mainly considered as indicators of myoglobin content and oxidation (Santé, 1993). In agreement with this statement, the present experiment showed that sheep breeds affected significantly the luminance of meat $(P<$ 0.05 ) and that higher $L^{*}$ values were associated with lower ultimate $\mathrm{pH}$ (see Tab. 4. and Fig. 1.). Although the current study showed that lightness was numerically higher in $L d$ muscle of $\mathrm{DA}$ lambs than that of IA animals (Tab. 4.) which agree with Wang et al. (2018) who declared that docked lambs presented higher $L^{*}$ values in $L d$ and $G m$ muscles than intact sheep with an insignificant effect of docking on redness $\left(a^{*}\right)$ and yellowness $\left(b^{*}\right)$ values. However, the relationship between luminosity and 
fat content in $L d$ muscle in docked animals could be due to the fact that, in this work, the high $L d$ ultimate $\mathrm{pH}$ of docked lambs compensated the positive effect of high fat content on meat lightness. Finally, it is noteworthy that $b^{*}$ values were significantly higher $(P<0.05)$ in $G m$ muscle than $B f$ and $L d$ muscles of all lambs under study (see Tab. 4.). This result was consistent with the finding that $G m$ muscle had greater fat content than $B f$ and $L d$ muscles (see Tab. 3). We suggest then i) that not only the lightness of meat is affected by the intramuscular fat but also the yellowness and ii) that intramuscular fat is not the only reason for differences found in the lightness of sheep meat; several factors seem to play an important role e.g. ultimate $\mathrm{pH}$. Due to the scarcity of information in this area of research, more investigations are needed to clarify the effect of fat tail docking sheep on muscular fat accumulation and consequently lightness of meat by determining the intensity of relationship between fat concentration, ultimate $\mathrm{pH}$ and CIE color readings ( $\left.\mathrm{L}^{*}, \mathrm{a}^{*}, \mathrm{~b}^{*}\right)$.

4.2.3 Water holding capacity: Experimental results obtained on water holding capacity of meat within breed, fat tail docking animals and muscle type are presented in table 5. Current results showed that breed affected significantly the drip loss and animals of IL group had lower values than Awassi sheep (IA and DA groups), $(P<0.05$ in Bf and $G m$ muscles and $P<0.01$ in $L d$ muscle). These results were consistent with the fact that high ultimate $\mathrm{pH}$ induced low drip losses and consequently high water holding capacity (WHC). Moreover, Lacaune breed (IL) presented the highest ultimate $\mathrm{pH}$ in the three studied muscles. Indeed, as $\mathrm{pH}$ decreases and approaching the iso- electrical point $(\mathrm{pH}=5.5)$ of proteins, the repulsion forces between myofibrils decrease and thick and thin filaments move closer together pushing the cell water out. Thus, fluid is lost from muscle fibers leading to a reduction in meat WHC. The current study showed that docking influenced the WHC of Awassi sheep meat. The drip loss in $L d$ muscle of DA animals was significantly lower than that of IA group (1.42 \pm 0.03 vs. $1.49 \pm 0.03 \% ; P<0.01)$. It is very likely that the positive effect of docking on the WHC was related to the high fat content and exacerbated by the high ultimate $\mathrm{pH}$ measured in the $L d$ muscle of DA lambs. Thawing and cooking losses in Bf, $L d$ and $G m$ muscles of lambs were neither affected by breed nor by tail docking. Nevertheless, a trend toward a significant effect of docking on thawing loss was recorded in $L d$ muscle; thawing loss tend to be lower in $L d$ muscle of DA animals than that of IA and IL groups $(P=$ 0.06). Those findings agree with El Rammouz et al. (2004) who recorded a significant correlation between drip loss and ultimate $\mathrm{pH}(\mathrm{r}=-0.56 ; \mathrm{P}<$ $0.01)$ in turkey toms. Moreover this experiment result's agreed with Wang et al. (2018) who reported that drip loss of lamb meat is closely related to muscle fat concentration and confirmed that drip losses were decreased in $L d$ and $G m$ muscles by 2.3 and $9.9 \%$, respectively, in docked sheep, finally he confirmed that neither the thawing loss nor the cooking loss were affected by docking. Some authors stated that fat concentration is indeed a potential contributor to the WHC of raw meat by surrounding the muscle fibers and the water, the deterioration of fat by the presser and the heat when thawing and cooking (Lawrie and Leward, 2006). Regarding cooking loss, Hoffman et al. (2003) reported similar results and detected insignificant difference between sheep breeds. In contrast, Abdullah et al. (2011) published a significant effect of breed on cooking loss in ovine meat. 
Table. 4: Meat color (L*, a*, b*; measured at 24 and 48 h post mortem) in Bf, Ld and Gm muscles ${ }^{1}$ of intact and tail docked Awassi (IA and DA, respectively) and Lacaune (IL) lambs sheep.

\begin{tabular}{|c|c|c|c|c|c|c|c|c|c|c|c|c|}
\hline & \multicolumn{4}{|l|}{$L^{*}$} & \multicolumn{4}{|l|}{$\mathrm{a}^{*}$} & \multicolumn{4}{|l|}{ b* } \\
\hline & \multicolumn{2}{|l|}{$\underline{\text { Awassi }}$} & \multicolumn{2}{|l|}{ Lacaune } & \multicolumn{2}{|l|}{ Awassi } & \multicolumn{2}{|l|}{ Lacaune } & \multicolumn{2}{|l|}{$\underline{\text { Awassi }}$} & \multicolumn{2}{|l|}{ Lacaune } \\
\hline & IA & DA & IL & $s$ & IA & DA & IL & $S$ & IA & DA & IL & $s$ \\
\hline \multicolumn{13}{|l|}{24 h p.m. } \\
\hline$B F$ & $42.22 \pm 3.01 \mathbf{a}^{\mathbf{x}}$ & $43.04 \pm 3.88 \mathbf{a}^{\mathbf{x}}$ & $38.21 \pm 3.22^{\mathrm{y}}$ & * & $19.51 \pm 3.35$ & $19.45 \pm 4.95$ & $18.90 \pm 4.11$ & NS & $10.36 \pm 2.80 \mathbf{a}$ & $9.68 \pm 3.01 \mathrm{a}$ & $10.55 \pm 3.18 \mathbf{a}$ & NS \\
\hline Ld & $38.96 \pm 2.41 \mathbf{b}^{\mathbf{x}}$ & $39.52 \pm 1.44 \mathbf{b}^{\mathbf{x}}$ & $36.31 \pm 2.59 \mathrm{y}$ & * & $20.75 \pm 3.91$ & $18.92 \pm 4.16$ & $20.79 \pm 2.70$ & NS & $12.01 \pm 1.45 \mathbf{a}$ & $11.95 \pm 2.81 \mathbf{a}$ & $11.84 \pm 2.81 \mathbf{a}$ & NS \\
\hline Gm & $42.24 \pm 3.11 \mathbf{a}^{\mathbf{x}}$ & $43.25 \pm 3.36 \mathbf{a}^{\mathbf{x}}$ & $36.34 \pm 2.26^{y}$ & * & $18.87 \pm 3.47$ & $17.80 \pm 1.71$ & $18.19 \pm 3.71$ & NS & $14.71 \pm 2.09 b$ & $14.56 \pm 1.79 b$ & $14.37 \pm 1.50 \mathrm{~b}$ & $N S$ \\
\hline$S$ & * & * & NS & & NS & NS & $P=0.08$ & & * & * & * & \\
\hline \multicolumn{13}{|l|}{48 h p.m. } \\
\hline$\frac{B f}{L d}$ & $\begin{array}{l}44.31 \pm 4.00 \mathbf{a}^{\mathbf{x}} \\
39.96 \pm 1.41 \mathbf{b}^{\mathbf{x}}\end{array}$ & $\begin{array}{l}44.30 \pm 3.45 \mathbf{a}^{\mathbf{x}} \\
40.21 \pm 2.10 \mathbf{b}^{\mathbf{x}}\end{array}$ & $\begin{array}{l}39.65 \pm 2.00 \mathrm{y} \\
37.48 \pm 2.41^{\mathrm{y}}\end{array}$ & * & $\begin{array}{l}17.19 \pm 2.38 \\
18.89 \pm 1.49\end{array}$ & $\begin{array}{l}18.20 \pm 3.38 \\
18.85 \pm 3.46\end{array}$ & $\begin{array}{l}18.30 \pm 2.57 \\
18.98 \pm 3.11\end{array}$ & $\begin{array}{l}\text { NS } \\
\text { NS }\end{array}$ & $\begin{array}{l}10.38 \pm 2.81 \mathbf{a} \\
12.49 \pm\end{array}$ & $\begin{array}{l}11.10 \pm 2.66 \mathbf{a} \\
12.02 \pm 1.74 \mathbf{a}\end{array}$ & $\begin{array}{l}11.65 \pm 2.62 \mathbf{a} \\
12.00 \pm 1.76 \mathbf{a}\end{array}$ & $\begin{array}{l}\text { NS } \\
\text { NS }\end{array}$ \\
\hline & & & & & & & & & $2.40 \mathrm{ab}$ & & & \\
\hline Gm & $42.12 \pm 0.87 \mathbf{a}^{\mathbf{x}}$ & $43.61 \pm 2.79 \mathbf{a}^{\mathbf{x}}$ & $39.15 \pm 3.39 \mathrm{y}$ & * & $18.43 \pm 1.79$ & $18.63 \pm 1.96$ & $18.60 \pm 1.78$ & NS & $14.11 \pm 1.64 \mathrm{~b}$ & $14.98 \pm 2.40 \mathbf{b}$ & $14.45 \pm 2.36 \mathbf{b}$ & NS \\
\hline$S$ & * & * & NS & & NS & NS & NS & & * & * & * & \\
\hline
\end{tabular}

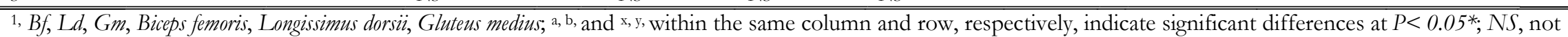
significant.

Table. 5: Effect of breed and fat tail docking on water holding capacity (WHC; drip, thawing and cooking losses) in $B f, L d$ and $G m$ muscles ${ }^{1}$ of sheep lambs.

\begin{tabular}{|c|c|c|c|c|c|c|c|c|c|c|c|c|}
\hline & \multicolumn{4}{|c|}{ Drip loss $(\%, 48$ h p.m.) } & \multicolumn{4}{|c|}{ Thawing loss (\%) } & \multicolumn{4}{|c|}{ Cooking loss (\%) } \\
\hline & \multicolumn{2}{|c|}{ Awassi } & \multicolumn{2}{|l|}{$\underline{\text { Lacaune }}$} & \multicolumn{2}{|c|}{ Awassi } & \multicolumn{2}{|l|}{$\underline{\text { Lacaune }}$} & \multicolumn{2}{|c|}{$\underline{\text { Awassi }}$} & \multicolumn{2}{|l|}{ Lacaune } \\
\hline & IA & DA & IL & $s$ & IA & DA & IL & $s$ & IA & DA & IL & $S$ \\
\hline$\overline{B F}$ & $1.55 \pm 0.04 \mathbf{a}^{\mathbf{x}}$ & $1.53 \pm 0.03 \mathbf{a}^{\mathbf{x}}$ & $1.43 \pm 0.02 \mathbf{a}^{\mathbf{y}}$ & * & $4.81 \pm 0.13$ & $4.74 \pm 0.18$ & $4.73 \pm 0.12$ & NS & $27.21 \pm 0.63$ & $27.44 \pm 0.41$ & $27.00 \pm 0.74$ & NS \\
\hline Ld & $1.49 \pm 0.03 \mathbf{b}^{\mathbf{x}}$ & $1.42 \pm 0.03 \mathbf{b}^{\mathbf{y}}$ & $1.42 \pm 0.03 \mathbf{a}^{\mathbf{z}}$ & ** & $4.82 \pm 0.12$ & $4.72 \pm 0.11$ & $4.81 \pm 0.14$ & $P=0.06$ & $27.48 \pm 0.60$ & $27.23 \pm 0.66$ & $27.31 \pm 0.79$ & NS \\
\hline$G m$ & $1.53 \pm 0.03 \mathbf{a}^{\mathbf{x}}$ & $1.52 \pm 0.03 \mathbf{a}^{\mathbf{x}}$ & $1.46 \pm 0.02 \mathbf{b}^{\mathbf{y}}$ & * & $4.78 \pm 0.15$ & $4.77 \pm 0.12$ & $4.77 \pm 0.15$ & NS & $27.33 \pm 0.71$ & $27.12 \pm 0.61$ & $26.88 \pm 0.53$ & NS \\
\hline$S$ & * & * & * & & NS & NS & NS & & NS & NS & NS & \\
\hline
\end{tabular}

1, Bf, Ld, Gm, Biceps femoris, Longissimus dorsii, Gluteus medius; a, b, and x, y, within the same column and row, respectively, indicate significant differences at P<0.05*; NS, not significant. 
Bendall, 1947). After that, meat ageing occurs (Abdullah et al., 2011) which is associated with post mortem proteolysis degradation by endogenous enzymes (Prado and De Felicio, 2010). Moreover, Cetin et al. (2012) reported that the muscle $\mathrm{pH}$ fall stopped and the Rigor achieved at $24 \mathrm{~h}$ post mortem followed by the tenderization of muscle (meat ageing) which lied between 24 and $72 \mathrm{~h}$ post mortem in lambs. However results of this study were slightly different than those reported by Burke and Apple (2007) who noted a significant difference between sheep breeds in terms of instrumental meat tenderness. However, concerning docking effect, this experiment agreed with Wang et al. (2018) who reported that the shear force of $L d$ muscle, in relation with fat level, was significantly reduced in docked lambs compared to intact animals (reduction of $12.15 \% ; P<0.01$ ). In accordance with our results and those of Wang et al. (2018), tenderness and drip loss are significantly correlated with the meat fat content. Moreover, Hopkins et al. (2006) mentioned that muscle fat concentration is an important indicator in meat quality related to smoothness and has a great influence on freshness and tenderness. the establishment of Rigor mortis (Bate- Smith and

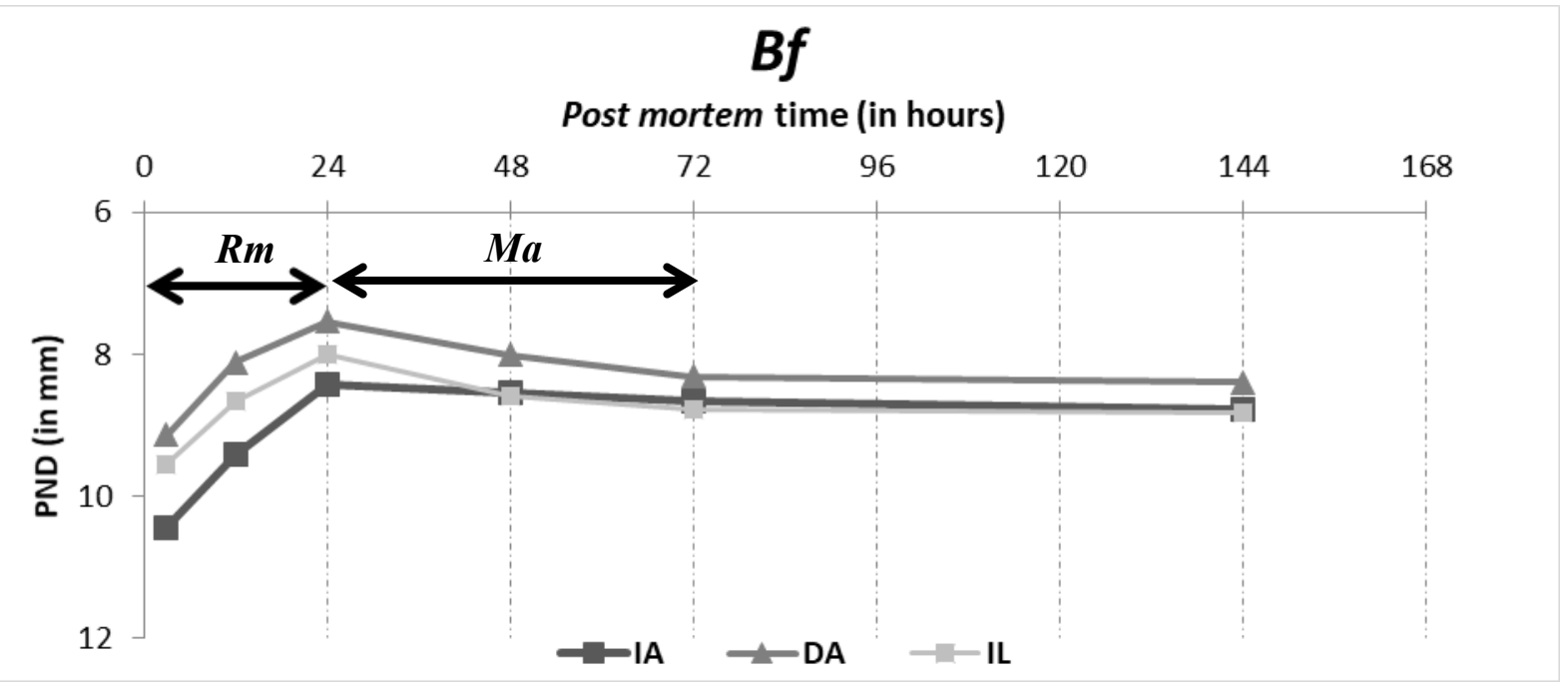




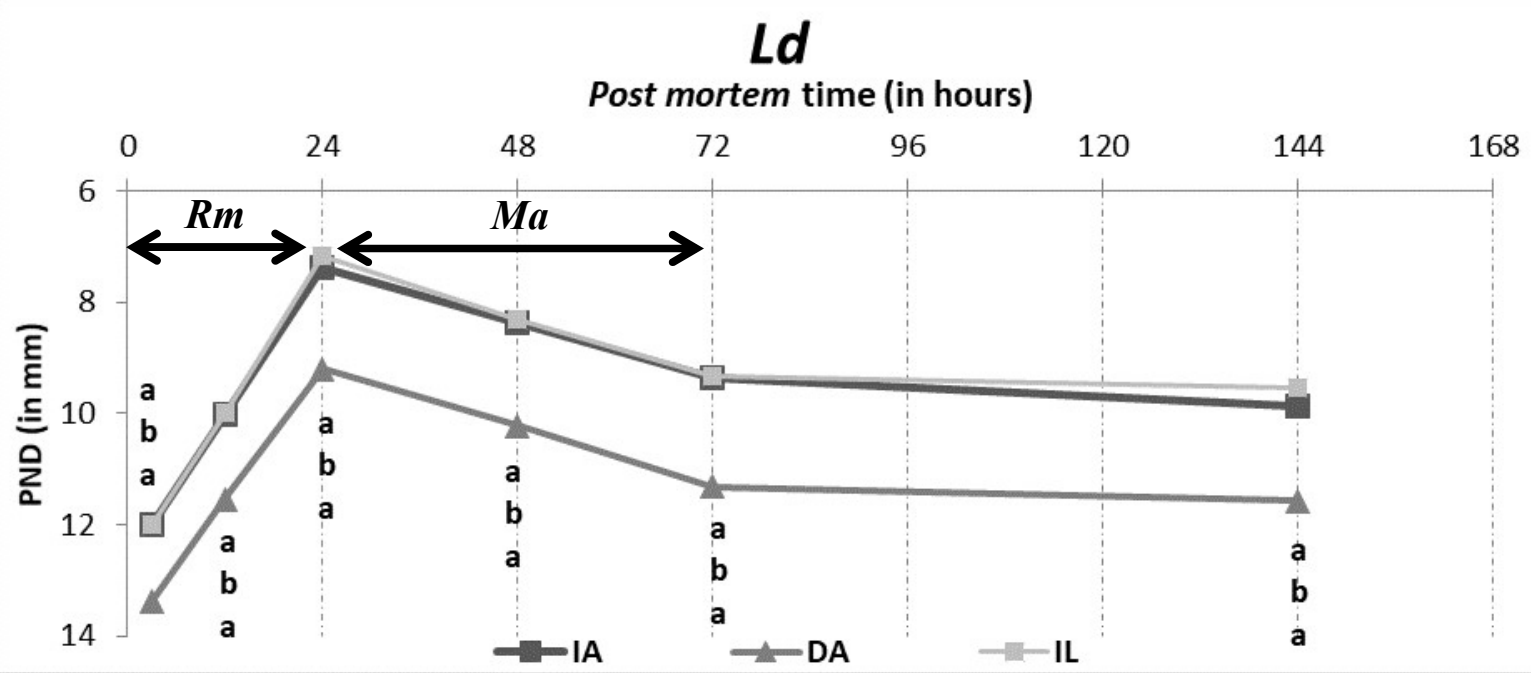

Gm

Post mortem time (in hours)

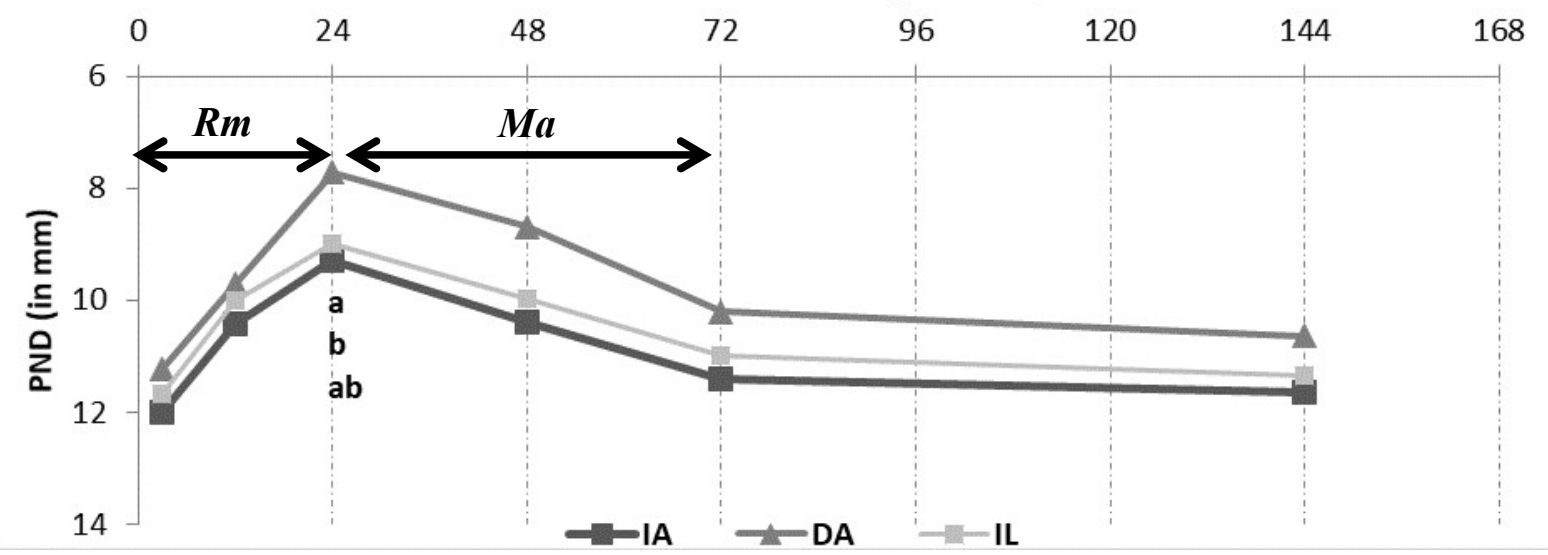

Figure. 2: Post mortem evolution of meat tenderness in $B f, L d$ and $G m$ muscles of intact (IA), fat tail docking Awassi (DA) and Lacaune (IL) sheep. ${ }^{a}$, b, different letters indicate significant difference at $P<0.05$. PND, penetrometer needle depth (mm); Rm, Rigor mortis; Ma, Meat ageing.

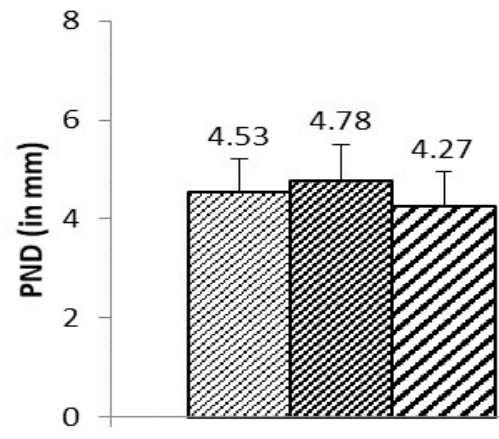

$\mathrm{Bf}$

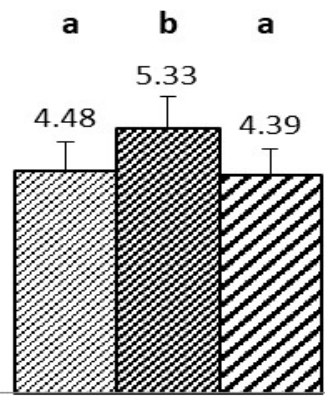

$\mathrm{Ld}$

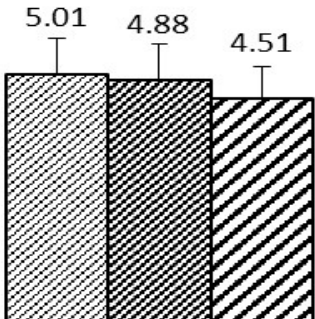

$\mathrm{Gm}$

QIA $\square \mathrm{DA} \boldsymbol{\nabla I L}$

Figure 3: Effect of breed and fat tailed docked on PND (Penetrometer needle depth; mm) of cooked meat in Bf, Ld and Gm muscles of intact (IA), fat tail docking Awassi (DA) and Lacaune (IL) sheep. a,b, different letters indicate significant difference at $P<0.05$. 


\section{CONCLUSION}

Results of the current experiment showed that lamb's breed affected meat quality. It seems that Awassi sheep meat has a longer shelf life and a better flavor and aroma than Lacaune lambs. Awassi tail docking enhances the accumulation of fat in $L d$ muscle and induces better WHC and tenderness.

\section{REFERENCES}

Abdelqader A, Irshaid R, Tabbaa M J, Abuajamieh M, Titi H. and Al-Fataftah A: 2017. Factors influencing Awassi lambs survivorship under fields' conditions. Livestock Science 199: 1-6.

Abdullah A Y, Qudsieh R I. and Nusairat B M: 2011. Effect of crossbreeding with exotic breeds on meat quality of Awassi lambs. Livestock Science 142(1):121-127.

Abi Saab S, Sleiman F T, Kallassy N, Darweesh W. and Aad P: 2010. Effect of adaptation and heat stress on reproductive performances of fat-tail Awassi rams in eastern Mediterranean. Lebanese Science Journal 12(1): 31-44.

Ablikim B, Liu Y, Kerim A, Shen P, Abdurerim P. and Zhou G H: 2016. Effects of breed, muscle type, and frozen storage on physicochemical characteristics of lamb meat and its relationship with tenderness. CyTA Journal of Food, 14(1), 109-116.

AOAC: 1995. Official methods of analysis 16th Ed. Association of Official Analytical Chemists. Washington DC, USA.

Bate-Smith EC. and Bendall J R: 1947. Rigor mortis and adenosine triphosphate. Journal of Physiologie 106(2): 177-185.

Becila S: 2002. Étude de l'influence des paramètres physico- chimiques sur la maturation de la viande d'agneau. [Ms]. Institut de la Nutrition, de l'Alimentation et des Technologies Agro- Alimentaires (INATAA), Mentouri University, Connstantine, Algeria. pp. 105.

Burke JM. and Apple J K: 2007. Growth performance and carcass traits of forage-fed hair sheep wether. Small Ruminant Research 67(2): 264-270.

Cetin O, Bingol E B, Colak H. and Hampikyan H: 2012. Effects of electrical stimulation on meat quality of lamb and goat meat. The Scientific World Journal 2012: 1-9.
The practicing of Awassi tail docking can be performed in Lebanon and would be appreciated by consumers. Further investigations in this area of research would be very useful to improve the capacity of controlling meat quality in Awassi sheep.

CIE: 1986. Colorimétrie (2nd Ed.), Commission Internationale de l'Eclairage, Publication CIE 15.2. Vienna, Austria.

El Rammouz R, Babile R. and Fernandez X: 2004. Effect of the ultimate $\mathrm{pH}$ on the physicochemical and biochemical characteristics of turkey breast muscle showing normal rate of post mortem $\mathrm{pH}$ fall. Poultry Science 83(10): 1750-1757.

Esenbuga N, Macit M. and Karaoglu M: 2009. Effect of breed on fattening performance, slaughter and meat quality characteristics of Awassi and Morkaraman lambs. Livestock Science 123(2): 255-260.

FAO: 2015. Statistical pocketbook world food and agriculture. Food and Agriculture Organization of the United Nations.

Farah L, Tabet E, Sadek L. and Abi Saab S: 2019. Effect of fat tail docking on growth, adaptation and fertility of Awassi ram lamb. Les Doctoriales 2019:73-86

Galal S, Gürsoy O. and Shaat I: 2008. Awassi sheep as a genetic resource and efforts for their genetic improvement. A review: Small Ruminant Research 79(2-3): 99-108.

Hernandez-Cruz L, Ramirez-Bribiesca J E, Guerrero-Legarreta M I, Hernandez-Mendo O, Crosby-Galvan M M. and HernandezCalva L M: 2009. Effects of crossbreeding on carcass and meat quality of Mexican lambs. Arq. Bras. Med. Vet. Zootec. 61(2): 475-483.

Hoffman L C, Muller M, Cloete S W P. and Schmidt D: 2003. Comparison of six crossbred lamb types: Sensory, physical and nutritional meat quality characteristics. Meat Science 65(4): 1265-1274.

Holloway I J, Purchas RW, Power MT. and Thomson NA: 1994. A comparison of the carcass and meat quality of Awassi- cross and Texel-cross ram lambs. Proceedings of the New Zealand Society of Animal Production 54: 209-213. 
Honikel KO: 1998. Reference methods for the assessment of physical characteristics of meat. Meat Science 49(4): 447-457.

Hopkins D L, Hegarty R, Walker P. and Pethick D: 2006. Relationship between animal age, intramuscular fat, cooking loss, $\mathrm{pH}$, shear force and eating quality of aged meat from sheep. Australian Journal of Experimental Agriculture 46(7): 879-884.

Hopkins D L, Fogarty N M. and Mortimer S I: 2011. Genetic related effects on sheep meat quality. Small Ruminant Research 101(1): 160-172.

Jandasek J, Milerski M. and Lichovnikova M: 2014. Effect of sire breed on physicochemical and sensory characteristics of lamb meat. Meat Science 96(1): 88-93.

Jeacocke RE: 1977. Continuous measurement of the $\mathrm{pH}$ of beef muscle in intact beef carcass. International Journal of Food Science Technology 12(4): 375-386.

Kyanzad MR: 2001. Crossbreeding of the three Iranian sheep breeds with emphasis on growth and carcass characteristics of the lambs. Doctoral dissertation, Ph.D. Thesis. University of Utra- Malaysia.

Lawrie RA. and Leward DA: 2006. Lawrie's meat science. Woodhead published limited. 7th edition. Cambridge, pp. 349.

Martinez- Cerezo S, Sañudo C, Medel I. and Olleta J L: 2005. Breed, slaughter weight and ageing time effects on sensory characteristics of lamb. Meat Science 69(3): 571-578.

Moharrery A: 2007. Effect of docking and energy of diet on carcass fat characteristics in fattailed Badghisian sheep. Small Ruminant Research 69: 208-216.

Nik-Khah A: 1984. The growth and carcass quality of Afshari, Turker and Mehraban lambs on different diets. Proceedings of the Australian Society of Animal Production15: 489-499.

Prado C S. and De Felício P E: 2010. Effects of chilling rate and spray- chilling on weight loss and tenderness in beef strip loin steaks. Meat Science 86(2): 430-435.

Santé V: 1993. Instabilité de la couleur de la viande de dinde (Meleagris gallopavo): Influence de la Rigor mortis, du mode de conditionnement et d'antioxydants. Ph.D. Thèses. Universite de Clermont II, France, pp: 132.
Safdarian M, Zamiri M J, Hashemi M. and Noorolahi H: 2008. Relationship of fat-tail dimensions with fat-tail weight and carcass characteristics at different slaughter weights of Torki- ghashghaii sheep. Meat Science 80(3): 686-689.

Vatankah M. and Talebi M A: 2008. Genetic parameters of body weight and fat-tail measurements in lambs. Small Ruminant research 75:1-6.

Wang Y Q, Zhong R Z, Fang Y. and Zhou D W: 2018. Influence of tail docking on carcass characteristics, meat quality and fatty acid composition of fat- tail lambs. Small Ruminant Research 162: 17-21.

Webb E C. and O'Neill HA: 2008. The animal fat paradox and meat quality. Meat Science 80 (1): 28-36.

Yousefi A R, Kohram H, Shahneh A Z, Nik-khah A. and Campbell A W: 2012. Comparison of the meat quality and fatty acid composition of traditional fat-tailed (Chall) and tailed (Zel) Iranian sheep breeds. Meat Science 92: 417-422. 